\title{
Determination of rapid chlorination rate constants by a stopped-flow spectrophotometric competition kinetics method
}

\author{
Dean Song ${ }^{a, b}$, Huijuan Liu ${ }^{a, *}$, Zhimin Qiang ${ }^{a}$, Jiuhui Qu ${ }^{a}$ \\ a State Key Laboratory of Environmental Aquatic Chemistry, Research Center for Eco-Environmental Sciences, \\ Chinese Academy of Sciences, Beijing 100085, China \\ ${ }^{\mathrm{b}}$ University of Chinese Academy of Sciences, Beijing 100039, China
}

\section{A R T I C L E I N F O}

Article history:

Received 25 September 2013

Received in revised form

24 January 2014

Accepted 26 January 2014

Available online 19 February 2014

Keywords:

Chlorination kinetics

Stopped-flow

DPD

Competition kinetics

\begin{abstract}
A B S T R A C T
Free chlorine is extensively used for water and wastewater disinfection nowadays. However, it still remains a big challenge to determine the rate constants of rapid chlorination reactions although competition kinetics and stopped-flow spectrophotometric (SFS) methods have been employed individually to investigate fast reaction kinetics. In this work, we proposed an SFS competition kinetics method to determine the rapid chlorination rate constants by using a common colorimetric reagent, $\mathrm{N}, \mathrm{N}$-diethyl-p-phenylenediamine (DPD), as a reference probe. A kinetic equation was first derived to estimate the reaction rate constant of DPD towards chlorine under a given $\mathrm{pH}$ and temperature condition. Then, on that basis, an SFS competition kinetics method was proposed to determine directly the chlorination rate constants of several representative compounds including tetracycline, ammonia, and four $\alpha$-amino acids. Although $\mathrm{Cl}_{2} \mathrm{O}$ is more reactive than $\mathrm{HOCl}$, its contribution to the overall chlorination kinetics of the test compounds could be neglected in this study. Finally, the developed method was validated through comparing the experimentally measured chlorination rate constants of the selected compounds with those obtained or calculated from literature and analyzing with Taft's correlation as well. This study demonstrates that the SFS competition kinetics method can measure the chlorination rate constants of a test compound rapidly and accurately.
\end{abstract}

(c) 2014 Elsevier Ltd. All rights reserved.

\section{Introduction}

Chlorine is the most widely used chemical disinfectant around the world. It is cheap, stable and effective against many pathogens including bacteria and viruses. Hence, despite the formation of harmful chlorinated disinfection byproducts, chlorine will still act as a primary disinfectant in many countries. In recent years, the transformation and fate of various organic micropollutants during water chlorination have attracted increasing attentions (Deborde and von Gunten, 2008; Sharma, 2008; Sedlak and von Gunten, 2011). As a prerequisite, the kinetic rate constants of a micropollutant reacting towards chlorine should be determined,

\footnotetext{
* Corresponding author. Tel.: +8610 62849128; fax: +86 1062923541

E-mail address: hjliu@rcees.ac.cn (H. Liu).
} 
so as to predict the removal efficiency and identify the primary reaction sites of the micropollutant under certain experimental conditions (Gallard and von Gunten, 2002; Li and Zhang, 2012). However, the kinetic study presents a great challenge for researchers because the reaction between chlorine and an organic micropollutant generally proceeds sufficiently fast to preclude measurement by conventional batch/quench techniques.

Competition kinetics method, by using a reference compound whose rate constant towards a specific oxidant is already known, has been developed for kinetic study of many fast reactions (Acero et al., 2010; Wang et al., 2011). In this method, a test compound and a reference compound are simultaneously oxidized in an aqueous solution, and then their residual concentrations at pre-selected time intervals are quantified after instrumental separation (e.g., using liquid chromatography or gas chromatography techniques). By comparing to the available rate constant of the reference compound towards the applied oxidant, the rate constant of the test compound can be calculated. However, the frequent operations such as sample withdrawal, pretreatment, separation, and analysis are not only time-consuming but also labor-intensive. Stopped-flow spectrophotometric (SFS) method, which permits immediate and continuous observations of a fast reaction, appears to be a promising technique for studying fast reaction kinetics in an aqueous solution if there is no spectral interference between the reactants and the products (Qiang and Adams, 2004; Karnas et al., 2010).

It is well known that a commonly used colorimetric reagent, $\mathrm{N}, \mathrm{N}$-diethyl-p-phenylenediamine (DPD), can react rapidly with chlorine to yield a stable semi-quinoid cationic radical $\left(\mathrm{DPD} \cdot^{+}\right.$) called "Würster dye". This cationic radical has a strong absorbance at $510 \mathrm{~nm}$, where no spectral interference from most compounds can be observed (Michaelis, 1931; Zarei and Sovizi, 2011). Hence, this reaction has been adopted to determine aqueous chlorine concentration by a standard method (APHA, 1998; Moberg and Karlberg, 2000).

In the present study, a kinetic equation was first derived to estimate the reaction rate constants between chorine and DPD over a $\mathrm{pH}$ range of $6.75-8.90$ and a temperature range of $18-37{ }^{\circ} \mathrm{C}$, which are quite representative for water and wastewater treatment. Then, by using DPD as a reference probe, an SFS competition kinetics method was developed to determine directly the chlorination rate constants of tetracycline (TCN), ammonia, and four $\alpha$-amino acids. Finally, this developed method was validated through comparison of the experimentally determined chlorination rate constants of the selected compounds with those obtained from literature and through Taft's correlation analysis as well.

\section{Materials and methods}

\subsection{Chemicals}

All chemicals were at least of analytical grade and used as received. Sodium perchlorate, sodium borate, boric acid, ammonium chloride, glycine, and valine were obtained from Sinopharm Chemical Reagent Co., Ltd. (Shanghai, China). Alanine and leucine were purchased from Biosharp (Hefei,
China), DPD from Alfa Aesar China Co., Ltd. (Tianjin, China), and TCN from Jing Ke Hong Da Biotechnology Co., Ltd. (Beijing, China). Sodium hypochlorite ( $\mathrm{NaOCl},>10 \%$ available chlorine), supplied by Beijing Chemical Co. (Beijing, China), was used as the source of free chlorine (FC) and periodically standardized by a DPD colorimetric method (Li et al., 2007) with a UV-Visible spectrophotometer (Hitachi U-3010, Japan). Ultrapure water was produced by a Millipore Water Purification System (Advantage A10, Millipore) with a resistivity of $\geq 18.2 \mathrm{M} \Omega \mathrm{cm}$. This ultrapure water was used to prepare all reaction solutions in this study. The working solutions of DPD and $\mathrm{NaOCl}$ were freshly prepared every day and stored in amber bottles to prevent possible degradation by light. Sodium borate and boric acid were used as buffer to control the solution $\mathrm{pH}$ in the range of 6.75-8.90. An Orion 720A digital $\mathrm{pH}$ meter coupled with a combinational $\mathrm{pH}$ electrode (Thermo Scientific Inc., US) was used to measure the solution $\mathrm{pH}$.

\subsection{Experimental procedures}

A stopped-flow spectrophotometer (Model SX20, Applied Photophysics Ltd., Leatherhead, UK) was used to conduct kinetic experiments. The temperature of the reaction solution was controlled by an automatic water circulator (Thermo Fisher Scientific, Waltham, MA) connected to the stoppedflow's sample handling unit. An HP computer workstation was employed to control the stopped-flow and acquire the kinetic data as well. Kinetic traces were analyzed by the ProData software from Applied Photophysics Ltd. Unless otherwise stated, all kinetic experiments were carried out in triplicate at $24 \pm 1{ }^{\circ} \mathrm{C}$.

For the kinetic experiments, an equal volume of DPD and $\mathrm{NaOCl}$ solutions was simultaneously injected into the optical cell of the stopped-flow with two automatic syringes driven by compressed air. The DPD concentration was kept in at least 10 -fold excess of $\mathrm{NaOCl}$ concentration to simulate the pseudofirst-order reaction conditions. In a typical experiment, $0.20 \mathrm{mM}$ DPD and $0.01 \mathrm{mM} \mathrm{NaOCl}$ were employed. All reaction solutions were buffered with $10 \mathrm{mM}$ borate and adjusted to a desired $\mathrm{pH}$, and the ionic strength was controlled with $50 \mathrm{mM}$ $\mathrm{NaClO}_{4}$. The formation of DPD ${ }^{+}$was continuously monitored at $510 \mathrm{~nm}$ to determine the pseudo-first-order reaction rate constant. The second-order rate constant was then obtained by dividing the pseudo-first-order rate constant by the initial concentration of DPD.

The competition kinetics experiments were performed under the same experimental conditions as above (e.g., $10 \mathrm{mM}$ borate buffer, $50 \mathrm{mM} \mathrm{NaClO}_{4}$ for ionic strength control). TCN, ammonia, and four $\alpha$-amino acids were selected for chlorination tests. One working solution contained a test compound of varied concentrations and the reference compound (DPD, $0.20 \mathrm{mM}$ ), and the other contained $0.01 \mathrm{mM} \mathrm{NaOCl}$ solution. The two working solutions were simultaneously injected into the stopped-flow's optical cell through two automatic syringes and the reaction was initiated immediately. Because the test compound was able to compete for chlorine against $\mathrm{DPD}$, the formation rate of $\mathrm{DPD}^{\cdot+}$, as denoted by the $510 \mathrm{~nm}$ absorption peak, would slow down. Zero-point correction was applied to each kinetic trace to obtain an absolute absorbance change, which reflected the fraction of chlorine consumed by 
the reference compound (i.e. DPD). The second-order reaction rate constant of the test compound towards chlorine could then be readily calculated by comparing to the obtained rate constant of DPD.

The chlorination rate constants of the test compounds were either obtained directly (i.e. ammonia) or calculated (i.e. glycine, alanine and TCN) from literature at $\mathrm{pH} 7.5$ and $22-25^{\circ} \mathrm{C}$ (Qiang and Adams, 2004; Armesto et al., 1993; Wang et al., 2011). In addition, the effect of ionic strength on the chlorination rate constants of the test compounds was examined. In this work, the total ionic strength was approximately equal to $0.06 \mathrm{M}$ (i.e., $50 \mathrm{mM} \mathrm{NaClO}_{4}$ plus $10 \mathrm{mM}$ borate buffer). For chlorination of ammonia, our ionic strength was similar to that used by Qiang and Adams (2004), so the measured and literature rate constants are directly comparable. For chlorination of glycine and alanine, Armesto et al. (1993) used an ionic strength of about $0.50 \mathrm{M}$, much higher than our value. However, our analysis using Davies equation (applicable for ionic strength $<0.5 \mathrm{M}$ ) (Stumm and Morgan, 1996) shows that the chlorination rate constants of glycine and alanine are only changed by less than $5 \%$ when the ionic strength varies from 0.01 to $0.50 \mathrm{M}$, by taking the rate constants measured in this study (corresponding to about $0.06 \mathrm{M}$ ionic strength) as the reference. For chlorination of TCN, $10 \mathrm{mM}$ phosphate buffer was used, which was equal to an ionic strength of about $0.015 \mathrm{M}$ at pH 7.5 (Wang et al., 2011). Our analysis using Güntelberg equation (applicable for ionic strength $<0.1 \mathrm{M}$ ) (Stumm and Morgan, 1996) shows that the chlorination rate constant of TCN is only changed by less than $1 \%$ when the ionic strength varies from 0.01 to $0.06 \mathrm{M}$, by taking the rate constant measured in this study as the reference. Therefore, it can be reasonably concluded that the ionic strength ranging from 0.01 to $0.50 \mathrm{M}$ had an insignificant impact on the chlorination rate constants of the test compounds.

\section{Results and discussion}

\subsection{Determination of chlorination rate constants of DPD by SFS technique}

Under the simulated pseudo-first-order reaction conditions, the kinetic trace of DPD ${ }^{\cdot+}$ formation acquired by the stoppedflow at $510 \mathrm{~nm}$ could be fitted well to a single-exponential curve (Fig. 1, inset), revealing that the reaction was of firstorder with respect to FC. If plotting the pseudo-first-order rate constant $\left(k_{\mathrm{p}}\right)$ vs. the DPD concentration, a linear correlation with a zero intercept was observed (Fig. 1), which indicates that the reaction was also of first-order with respect to DPD. Thus, the formation rate of $\mathrm{DPD}^{{ }^{+}}$can be expressed as follows,

$\mathrm{d}\left[\mathrm{DPD}^{\bullet+}\right] / \mathrm{dt}=k[\mathrm{DPD}][\mathrm{FC}]$

where $k$ represents the second-order rate constant of DPD reacting with chlorine, which is $\mathrm{pH}$-dependent; [DPD] and [FC] are the total molar concentrations of DPD and FC, respectively.

Fig. 2 shows the experimental $k$ values in correspondence to different $\mathrm{pH}$ conditions. This $\mathrm{pH}$-dependent variation was

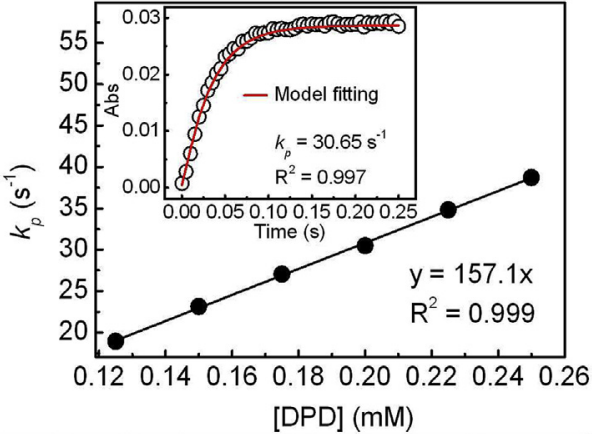

Fig. 1 - Plot of the pseudo-first-order reaction rate constant $\left(k_{\mathrm{p}}\right)$ as a function of DPD concentration $(\mathrm{pH}=8.6$, $T=24^{\circ} \mathrm{C}$ ). The inset shows a representative kinetic trace of $\mathrm{DPD}^{+}{ }^{+}$formation with time ([DPD $]_{\circ}=0.20 \mathrm{mM}$ ).

ascribed to the speciation of both DPD and FC on the basis of their dissociation constants $\left(\mathrm{pK}_{\mathrm{DPD}, 1}=2.95, \mathrm{pK}_{\mathrm{DPD}, 2}=8.46\right.$; $\mathrm{pK}_{\mathrm{HOCl}}=7.54,25^{\circ} \mathrm{C}$ ) (Morris, 1966; Moore et al., 1984). The kinetic model could be simplified based on the following facts: (1) the reaction related to $\mathrm{OCl}^{-}$could be neglected due to a much lower reactivity of $\mathrm{OCl}^{-}$than $\mathrm{HOCl}$ (Gerritsen and Margerum, 1990; Rebenne et al., 1996); and (2) the protonated amine was unreactive towards $\mathrm{HOCl} / \mathrm{OCl}^{-}$, just as it does not react with other electrophilic oxidants such as ozone and ferrate (Pryor et al., 1984; Qiang and Adams, 2004; Sharma et al., 2006). Therefore, the reaction of DPD with FC occurred predominantly between the neutral (i.e. unprotonated) forms of both reactants (see Fig. S1 for detailed information), and the second-order rate constant $(k)$ can be simplified to,

$k=\alpha_{1} \beta_{2} k_{\mathrm{HOCl}, \mathrm{DPD}}$

$\alpha_{1}=\left[\mathrm{H}^{+}\right] /\left(\left[\mathrm{H}^{+}\right]+\mathrm{K}_{\mathrm{HOCl}}\right)$

$\beta_{2}=K_{\mathrm{DPD}, 1} K_{\mathrm{DPD}, 2} /\left(\left[\mathrm{H}^{+}\right]^{2}+K_{\mathrm{DPD}, 1}\left[\mathrm{H}^{+}\right]+K_{\mathrm{DPD}, 1} K_{\mathrm{DPD}, 2}\right)$

where $\alpha_{1}$ and $\beta_{2}$ are the molar fractions of $\mathrm{HOCl}$ and the neutral DPD, respectively; and $k_{\text {HOCl,DPD }}$ represents the specific second-order rate constant correspondingly, which is independent of the solution pH. Fig. 2 demonstrates that the

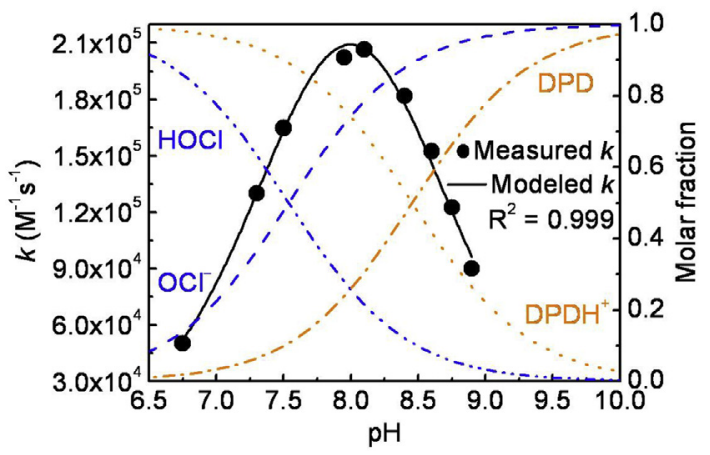

Fig. 2 - Model fitting of the second-order reaction rate constant of DPD with chlorine as a function of solution $\mathrm{pH}$ $\left(\mathrm{T}=24^{\circ} \mathrm{C}\right)$. 
experimentally measured $k$ values could be well predicted by Eq. (2). At a temperature of $24{ }^{\circ} \mathrm{C}$, the value of $k_{\text {HOCl,DPD }}$ was determined to be $(3.15 \pm 0.03) \times 10^{6} \mathrm{M}^{-1} \mathrm{~s}^{-1}$.

To examine the effect of temperature on the second-order rate constant, Eq. (2) can be rewritten by taking Arrhenius equation into consideration,

$k=\alpha_{1} \beta_{2} \operatorname{Aexp}\left(-E_{\mathrm{a}} / \mathrm{RT}\right)$

where $A=$ frequency factor, $E_{a}=$ activation energy, $R=$ universal gas constant $\left(8.314 \mathrm{~J} \mathrm{~K}^{-1} \mathrm{~mol}^{-1}\right)$, and $\mathrm{T}=$ absolute temperature $(\mathrm{K})$. More kinetic experiments were conducted at other temperatures $\left(18-37{ }^{\circ} \mathrm{C}\right)$, and the $k$ value exhibited a good linearity with the molar fraction product, $\alpha_{1} \beta_{2}$ (Fig. S2). The values of $A$ and $E_{a}$ were then calculated to be $1.44 \times 10^{9} \mathrm{M}^{-1} \mathrm{~s}^{-1}$ and $15.14 \mathrm{~kJ} \mathrm{~mol}^{-1}$, respectively (Fig. 3). Hence, Eq. (5) can be transformed to,

$k=\alpha_{1} \beta_{2} \times 1.44 \times 10^{9} \exp (-1821 / \mathrm{T})$

where the term " $\alpha_{1} \beta_{2}$ " reflects the effect of $\mathrm{pH}$, and the term "1.44 $\times 10^{9} \exp (-1821 / \mathrm{T})$ " reflects the effect of temperature. This kinetic equation can be used to predict the $k$ value when the $\mathrm{pH}$ and temperature conditions are known.

\subsection{Determination of chlorination rate constants of selected compounds by SFS competition kinetics method}

\subsubsection{Development of SFS competition kinetics method}

For the SFS competition kinetics, according to a recent review paper (Deborde and von Gunten, 2008), all chlorination reactions could be assumed to be of first-order with respect to each reactant (i.e., second-order in total) under the experimental conditions applied in this study. Hence, the competition kinetics was theoretically derived in Text S1, with the final equation given below,

$\mathrm{A}_{\mathrm{DPD}^{*+}, \mathrm{o}} / \mathrm{A}_{\mathrm{DPD}^{\bullet+}, \mathrm{t}}=1+k_{\mathrm{TC}}[\mathrm{TC}] /(k[\mathrm{DPD}])$

where $A_{\mathrm{DPD}^{*+}, \mathrm{o}}$ and $\mathrm{A}_{\mathrm{DPD}^{\bullet+}, t}$ are the absorbance changes in the absence and presence of a test compound (TC), respectively; and $k_{\mathrm{TC}}$ represents the second-order chlorination rate constant of the test compound.

It should be pointed out that in some cases, $\mathrm{Cl}_{2} \mathrm{O}$ could become the predominant reactive species of $\mathrm{FC}$ because it is more reactive than $\mathrm{HOCl}$ (Voudrias and Reinhard, 1988a, 1988b; Sivey et al., 2010). It was reported that $\mathrm{Cl}_{2} \mathrm{O}$ could be

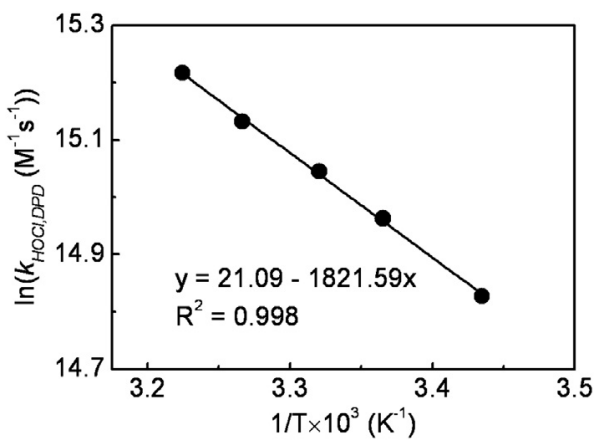

Fig. 3 - Arrhenius plot for the reaction between DPD and HOCl. generated through the following reaction with an equilibrium constant of $8.7 \times 10^{-3} \mathrm{M}^{-1}$ (Sivey et al., 2010),

$2 \mathrm{HOCl} \leftrightarrow \mathrm{Cl}_{2} \mathrm{O}+\mathrm{H}_{2} \mathrm{O}$

Consequently, the contribution ratio of $\mathrm{Cl}_{2} \mathrm{O}\left(\mathrm{R}_{\mathrm{Cl} 2 \mathrm{O}}\right)$ to the overall chlorination kinetics of a test compound can be deduced as follows,

$\mathrm{R}_{\mathrm{Cl}_{2} \mathrm{O}}=k_{\mathrm{Cl}_{2} \mathrm{O}}\left[\mathrm{Cl} \mathrm{O}_{2} \mathrm{O}\right] /(k[\mathrm{FC}])=8.7 \times 10^{-3} k_{\mathrm{Cl}_{2} \mathrm{O}}[\mathrm{HOCl}]^{2} /(k[\mathrm{FC}])$

or,

$\mathrm{R}_{\mathrm{Cl}_{2} \mathrm{O}}=8.7 \times 10^{-3} \alpha_{1}^{2} k_{\mathrm{Cl}_{2} \mathrm{O}}[\mathrm{FC}] / k$

where $k_{\mathrm{Cl} 2 \mathrm{O}}$ represents the second-order reaction rate constant of $\mathrm{Cl}_{2} \mathrm{O}$ with the test compound.

In this work, the upper limit of [HOCl] was $8.6 \mu \mathrm{M}$, which occurred at pH 6.75 and a typical FC (total chlorine) concentration of $10 \mu \mathrm{M}$. Since $\mathrm{Cl}_{2} \mathrm{O}$ is highly reactive, $k_{\mathrm{Cl} 2 \mathrm{O}}$ could approach a rate constant of diffusion control (i.e. $1 \times 10^{9} \mathrm{M}^{-1} \mathrm{~s}^{-1}$ ) (Sivey and Roberts, 2012). The $k$ value was measured as $(5.03 \pm 0.02) \times 10^{4} \mathrm{M}^{-1} \mathrm{~s}^{-1}$ at $\mathrm{pH} 6.75$ (Fig. 2). Hence, the $R_{\mathrm{Cl} 2 \mathrm{O}}$ was calculated to be only $0.13 \%$ under the experimental conditions applied in this study (Fig. S3). It is seen that the contribution of $\mathrm{Cl}_{2} \mathrm{O}$ to the overall chlorination kinetics of a test compound could be neglected in this study.

\subsubsection{Determination of chlorination rate constant of tetracycline}

As a "proof of concept" experiment, TCN was first selected as a test compound due to its ubiquitous occurrence in the environment and potential health risk to human (Kang et al., 2011; Pan et al., 2011; Zhang and Zhang, 2011). The typical kinetic traces of $\mathrm{DPD}^{\cdot+}$ formation in the presence of TCN with various concentrations are illustrated in the inset of Fig. 4. A plot of the absorbance ratio $\left(A_{\mathrm{DPD}^{*+}, \mathrm{o}} / \mathrm{A}_{\mathrm{DPD}^{*+}, t}\right)$ against the molar concentration ratio ([TCN]/[DPD]) yielded a straight line, with a slope (i.e. $k_{\mathrm{TCN}} / k ; k_{\mathrm{TCN}}$ denotes the second-order reaction rate constant of TCN with chlorine) equaling 1.89 and an intercept equaling $1\left(R^{2}=0.999\right)$ (Fig. 4). This plot well substantiates the applicability of the SFS competition kinetics method (i.e. Eq. (7)) proposed above. From the previously determined rate constant $k$, i.e., $(1.65 \pm 0.01) \times 10^{5} \mathrm{M}^{-1} \mathrm{~s}^{-1}$ (Fig. 2), the value of

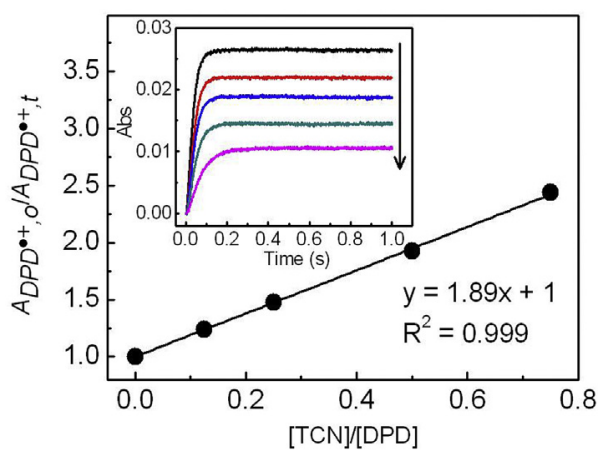

Fig. 4 - Transformed competition kinetics for the chlorination of $\mathrm{TCN}\left(\mathrm{pH}=7.5, \mathrm{~T}=24^{\circ} \mathrm{C}\right)$. The inset shows the kinetic traces of $\mathrm{DPD}^{+}{ }^{+}$formation at an initial DPD concentration of $0.20 \mathrm{mM}$ and various TCN concentrations $(0,0.025,0.05,0.10$ and $0.15 \mathrm{mM}$, from top to bottom). 
$k_{\mathrm{TCN}}$ could be readily calculated as $3.12 \times 10^{5} \mathrm{M}^{-1} \mathrm{~s}^{-1}$ at $24^{\circ} \mathrm{C}$, which is notably lower than $5.87 \times 10^{5} \mathrm{M}^{-1} \mathrm{~s}^{-1}$ as determined by the competition kinetics method at $22 \pm 1{ }^{\circ} \mathrm{C}$ (Wang et al., 2011). A possible reason could be that the conventional competition kinetics method requires an extra time for sample taking and handling, which makes the real reaction time a little longer than that assumed and thus easily leads to an overestimation of the chlorination rate constants. By contrast, the SFS technique assisted competition kinetics method, as developed in this study, can monitor fast chlorination reactions in real time and continuously, thus yielding more accurate results.

In addition, it is noted that small absorbance decay could be observed for the kinetic traces if the reaction time was extended (data not shown). Similar color-fading phenomena were observed for other stable radicals (Jones et al., 2009) and have been applied to evaluate the antioxidant activity in response to various compounds (e.g. drugs) (Liu, 2010). In this work, with the assistance of the SFS technique, each kinetic trace was rapidly acquired in $1 \mathrm{~s}$ (Fig. 4, inset) and the color-fading process could be avoided. This minimizes the potential error in determination of the chlorination rate constant of a test compound.

\subsubsection{Determination of chlorination rate constants of ammonia, glycine and alanine}

Similar to TCN, the second-order chlorination rate constants of ammonia, glycine and alanine were determined to be $1.17 \times 10^{4}$, $9.13 \times 10^{4}$ and $5.82 \times 10^{4} \mathrm{M}^{-1} \mathrm{~s}^{-1}$, respectively (Fig. S4), which are comparable to those $\left(1.80 \times 10^{4}, 1.23 \times 10^{5}\right.$ and $6.69 \times 10^{4} \mathrm{M}^{-1} \mathrm{~s}^{-1} ; 25{ }^{\circ} \mathrm{C}$ ) directly obtained (i.e. ammonia) or calculated (i.e. glycine and alanine) from literature by taking $\mathrm{pK}_{\mathrm{HOCl}}=7.54$ and the $\mathrm{pK}_{a}$ values listed in Table 1 (Armesto et al., 1993; Qiang and Adams, 2004). Fig. 5 shows a good correlation between the rate constants determined in this study and obtained or calculated from literature $\left(R^{2}=0.999\right)$. Previous studies have shown that the second-order rate constants of most rapid chlorination reactions ranged from $10^{4}$ to $10^{6} \mathrm{M}^{-1} \mathrm{~s}^{-1}$ (Deborde and von Gunten, 2008; Sharma, 2008), which confirms the applicability of the developed SFS competition kinetics method.

\subsubsection{Model validation through Taft equation}

The Taft equation, which establishes a linear free energy relationship commonly used to study the reaction mechanisms and develop the quantitative structure relationships for

\begin{tabular}{|c|c|c|c|c|}
\hline Parameters & Glycine & Alanine & Leucine & Valine \\
\hline $\begin{array}{l}\mathrm{pK}_{a, 1}, \mathrm{pK}_{a, 2}{ }^{\mathrm{a}} \\
\mathrm{k}_{\mathrm{HOCl}, \mathrm{AA}}\left(\mathrm{M}^{-1} \mathrm{~s}^{-1}\right)^{\mathrm{b}} \\
k_{\mathrm{AA}}\left(\mathrm{M}^{-1} \mathrm{~s}^{-1}\right)^{\mathrm{c}} \\
\text { Substituting group } \\
\sigma^{* \mathrm{~d}}\end{array}$ & $\begin{array}{l}2.34,9.6 \\
2.23 \times 10^{7} \\
9.13 \times 10^{4} \\
\mathrm{H} \\
0.49\end{array}$ & $\begin{array}{l}2.34,9.69 \\
1.80 \times 10^{7} \\
5.82 \times 10^{4} \\
\mathrm{CH}_{3} \\
0\end{array}$ & $\begin{array}{l}2.36,9.6 \\
1.63 \times 10^{7} \\
6.70 \times 10^{4} \\
i-\mathrm{C}_{4} \mathrm{H}_{9} \\
-0.12\end{array}$ & $\begin{array}{l}2.32,9.62 \\
1.53 \times 10^{7} \\
6.02 \times 10^{4} \\
i-\mathrm{C}_{3} \mathrm{H}_{7} \\
-0.19\end{array}$ \\
\hline \multicolumn{5}{|c|}{$\begin{array}{l}\text { a } \mathrm{Na} \text { and Olson (2007). } \\
\text { b Specific second-order rate constant. } \\
\text { c Second-order rate constant determined in this study. } \\
\text { d Davis (1967). }\end{array}$} \\
\hline
\end{tabular}
chlorination of four selected $\alpha$-amino acids $(\mathrm{pH}=7.5$, $\left.\mathbf{T}=24^{\circ} \mathbf{C}\right)$.

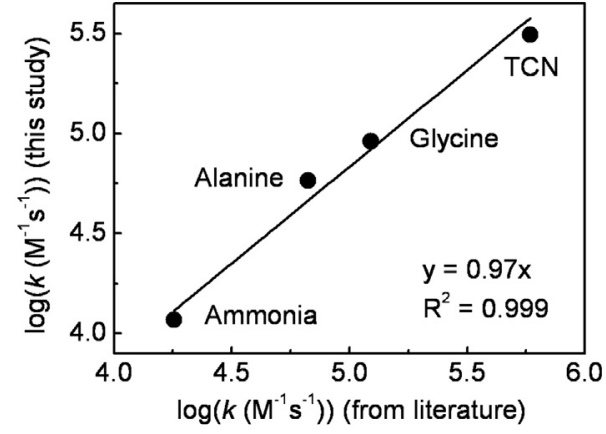

Fig. 5 - Correlation between the rate constants determined in this study and obtained or calculated from literature ( $\left.\mathrm{pH}=7.5, \mathrm{~T}=24 \pm 1^{\circ} \mathrm{C}\right)$.

organic compounds, is expressed as follows (Taft, 1952; Abia et al., 1998),

$\log \left(k_{\mathrm{TC}} / k_{\mathrm{Ref}}\right)=\rho^{*} \sigma^{*}+\delta \mathrm{E}_{\mathrm{s}}$

where $\log \left(k_{\mathrm{TC}} / k_{\mathrm{Ref}}\right)$ is the logarithmic ratio of the substituted reaction rate compared to the reference reaction rate; $\rho^{*}$ is the sensitivity factor for the reaction to polar effects; $\sigma^{*}$ is the polar substituent constant that describes the field and inductive effects of the substituent; $\delta$ is the sensitivity factor for the reaction to steric effects; and $E_{\mathrm{s}}$ is the steric substituent constant. In addition to the direct comparison, Taft's correlation analysis was performed for the chlorination rate constants of selected $\alpha$-amino acids.

The apparent second-order chlorination rate constants $\left(k_{\mathrm{AA}}\right)$ of two more $\alpha$-amino acids (i.e., leucine and valine) were determined with the SFS competition kinetics method at $\mathrm{pH}$ 7.5 and $24^{\circ} \mathrm{C}$ (Fig. S5). By taking account of the speciation of both reactants (i.e., amino acid and $\mathrm{HOCl}$ ) under different $\mathrm{pH}$ conditions, $k_{\mathrm{AA}}$ could be correlated to the specific secondorder rate constant $\left(k_{\mathrm{HOCl}, \mathrm{AA}}\right)$ through the following equation,

$k_{\mathrm{AA}}=k_{\mathrm{HOCl}, \mathrm{AA}} \frac{\mathrm{K}_{\mathrm{a}, 1} \mathrm{~K}_{\mathrm{a}, 2}\left[\mathrm{H}^{+}\right]}{\left(\left[\mathrm{H}^{+}\right]^{2}+\mathrm{K}_{\mathrm{a}, 1}\left[\mathrm{H}^{+}\right]+\mathrm{K}_{\mathrm{a}, 1} \mathrm{~K}_{\mathrm{a}, 2}\right)\left(\left[\mathrm{H}^{+}\right]+\mathrm{K}_{\mathrm{HOCl}}\right)}$

where $K_{a, 1}$ and $K_{a, 2}$ are the ionization constants of an amino acid. The $k_{\mathrm{AA}}$ and $k_{\mathrm{HOCl}, \mathrm{AA}}$ values of four selected $\alpha$-amino acids are listed in Table 1.

By taking alanine as reference, the relative $\sigma^{*}$ values of glycine, leucine and valine were determined to be $0.49,-0.12$ and -0.19 , respectively (Table 1$)$. The Taft's correlation between the $\log k_{\mathrm{HOCl}, \mathrm{AA}}$ and $\sigma^{*}$ values shows a good linearity (Fig. 6), suggesting the same chlorination mechanism for the four selected $\alpha$-amino acids. In addition, the fitting curve has a positive slope (i.e. $\rho^{*}$ ), indicating that an electron-rich substituent would increase the reaction rate (Taft, 1952). However, the low $\rho^{*}$ value (i.e. 0.23 ) indicates that the chlorination of $\alpha$-amino acid had only a limited sensitivity to the substituent's polar effects. This result is consistent with the previous findings that the chlorination rate constants of primary amines conform to the Taft equation with a positive and low $\rho^{*}$ value (Deborde and von Gunten, 2008). Hence, the Taft's correlation analysis of the chlorination rate constants of four $\alpha$-amino acids further confirms the validity of the developed method. 


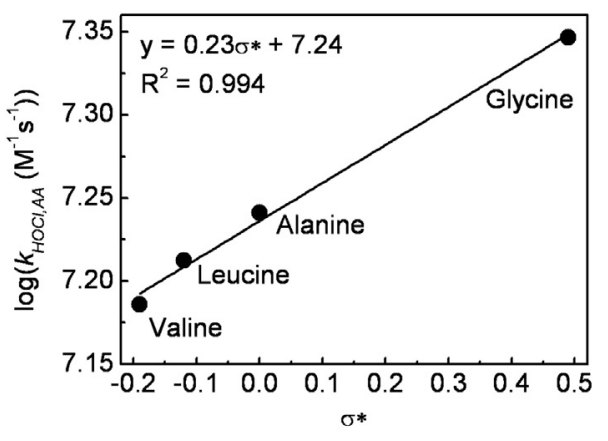

Fig. 6 - Taft's plot for the chlorination of four $\alpha$-amino acids $\left(T=24^{\circ} \mathrm{C}\right)$.

\section{Conclusions}

In this study, a kinetic equation was first derived to estimate the reaction rate constants between DPD and chorine under typical conditions for water and wastewater treatment. Then, by using DPD as a reference probe, an SFS competition kinetics method was developed to determine directly the chlorination rate constants of several selected compounds including TCN, ammonia, glycine, alanine, leucine, and valine. This developed method was further validated through comparison of the measured chlorination rate constants with those obtained or calculated from literature and through Taft's correlation analysis as well. In addition, this study also provides a possibility of investigating fast reaction kinetics by use of other suitable colorimetric reagents (as a reference probe) in combination with the SFS technique.

\section{Acknowledgments}

This project was supported by the National Science Fund for Distinguished Young Scholars of China (Grant No. 51225805) and the Fund for the Creative Research Groups of China (Grant No. 51221892).

\section{Appendix A. Supplementary data}

Supplementary data related to this article can be found at http://dx.doi.org/10.1016/j.watres.2014.01.048.

\section{REFERENCES}

Abia, L., Armesto, X.L., Canle, M., Garcia, M.V., Santaballa, J.A., 1998. Oxidation of aliphatic amines by aqueous chlorine. Tetrahedron 54, 521-530.

Acero, J.L., Benitez, F.J., Real, F.J., Roldan, G., 2010. Kinetics of aqueous chlorination of some pharmaceuticals and their elimination from water matrices. Water Res. 44, 4158-4170.

American Public Health Association, American Water Works Association, Water Environment Association, 1998. Standard Methods for the Examination of Water and Wastewater. APHA, Washington, DC.
Armesto, X.L., Canle, M., Santaballa, J.A., 1993. $\alpha$-amino acids chlorination in aqueous media. Int. J. Chem. Kinet. 26, 1135-1141.

Davis, M.A., 1967. Group electronegativity and polar substituent constants. J. Org. Chem. 32, 1161-1163.

Deborde, M., von Gunten, U., 2008. Reactions of chlorine with inorganic and organic compounds during water treatment kinetics and mechanisms: a critical review. Water Res. 42, 13-51.

Gallard, H., von Gunten, U., 2002. Chlorination of phenols: kinetics and formation of chloroform. Environ. Sci. Technol. $36,884-890$.

Gerritsen, C.M., Margerum, D.W., 1990. Non-metal redox kinetics: hypochlorite and hypochlorous acid reactions with cyanide. Inorg. Chem. 29, 2757-2762.

Jones, K.G., Cooper, W.J., Mezyk, S.P., 2009. Bimolecular rate constant determination for the reaction of hydroxyl radicals with domoic and kainic acid in aqueous solution. Environ. Sci. Technol. 43, 6764-6768.

Kang, J., Liu, H.J., Zheng, Y.M., Qu, J.H., Chen, J.P., 2011. Application of nuclear magnetic resonance spectroscopy, Fourier transform infrared spectroscopy, UV-Visible spectroscopy and kinetic modeling for elucidation of adsorption chemistry in uptake of tetracycline by zeolite beta. J. Colloid Interface Sci. 354, 261-267.

Karnas, E., Kim, S.K., Johnson, K.A., Sessler, J.L., Ohkubo, K., Fukuzumi, S., 2010. Stopped-flow kinetic analysis of the interaction of cyclo[8]pyrrole with anions. J. Am. Chem. Soc. 132, 16617-16622.

Li, B., Qu, J.H., Liu, H.J., Hu, C.Z., 2007. Effects of copper(II) and copper oxides on THMs formation in copper pipe. Chemosphere 68, 2153-2160.

Li, B., Zhang, T., 2012. pH significantly affects removal of trace antibiotics in chlorination of municipal wastewater. Water Res. 46, 3703-3713.

Liu, Z.Q., 2010. Chemical methods to evaluate antioxidant ability Chem. Rev. 110, 5675-5691.

Michaelis, L., 1931. A potentiometric study of Würster's red and blue. J. Am. Chem. Soc. 53, 2953-2962.

Moberg, L., Karlberg, B., 2000. An improved N,N'-diethyl-pphenylenediamine (DPD) method for the determination of free chlorine based on multiple wavelength detection. Anal. Chem. Acta 407, 127-133.

Moore, H.E., Garmendia, M.J., Cooper, W.J., 1984. Kinetics of monochloramine oxidation of N,N-diethyl- $p$ phenylenediamine. Environ. Sci. Technol. 18, 348-353.

Morris, J.C., 1966. The acid ionization constant of HOCl from 5 to $35^{\circ}$. J. Phys. Chem. 70, 3798-3805.

Na, C.Z., Olson, T.M., 2007. Relative reactivity of amino acids with chlorine in mixtures. Environ. Sci. Technol. 41, 3220-3225.

Pan, X., Qiang, Z.M., Ben, W.W., Chen, M.X., 2011. Residual veterinary antibiotics in swine manure from concentrated animal feeding operations in Shandong Province, China. Chemosphere 84, 695-700.

Pryor, W.A., Giamalva, D.H., Church, D.F., 1984. Kinetics of ozonation. 2. Amino acids and model compounds in water and comparisons to rates in nonpolar solvents. J. Am. Chem. Soc. 106, 7094-7100.

Qiang, Z.M., Adams, C.D., 2004. Determination of monochloramine formation rate constants with stopped-flow spectrophotometry. Environ. Sci. Technol. 38, 1435-1444.

Rebenne, L.M., Gonzalez, A.C., Olson, T.M., 1996. Aqueous chlorination kinetics and mechanism of substituted dihydroxybenzenes. Environ. Sci. Technol. 30, 2235-2242.

Sedlak, D.L., von Gunten, U., 2011. The chlorine dilemma. Science 331, 42-43.

Sharma, V.K., Mishra, S.K., Nesnas, N., 2006. Oxidation of sulfonamide antimicrobials by ferrate (VI) $\left[\mathrm{Fe}^{\mathrm{VI}} \mathrm{O}_{4}^{2-}\right]$. Environ. Sci. Technol. 40, 7222-7227. 
Sharma, V.K., 2008. Oxidative transformations of environmental pharmaceuticals by $\mathrm{Cl}_{2}, \mathrm{ClO}_{2}, \mathrm{O}_{3}$, and $\mathrm{Fe}(\mathrm{VI})$ : kinetics assessment. Chemosphere 73, 1379-1386.

Sivey, J.D., McCullough, C.E., Roberts, A.L., 2010. Chlorine monoxide $\left(\mathrm{Cl}_{2} \mathrm{O}\right)$ and molecular chlorine $\left(\mathrm{Cl}_{2}\right)$ as active chlorinating agents in reaction of dimethenamid with aqueous free chlorine. Environ. Sci. Technol. 44, 3357-3362.

Sivey, J.D., Roberts, A.L., 2012. Assessing the reactivity of free chlorine constituents $\mathrm{Cl}_{2}, \mathrm{Cl}_{2} \mathrm{O}$, and $\mathrm{HOCl}$ toward aromatic ethers. Environ. Sci. Technol. 46, 2141-2147.

Stumm, W., Morgan, J.J., 1996. Aquatic Chemistry: Chemical Equilibria and Rates in Natural Waters, third ed. WileyInterscience, p. 103.

Taft, R.W., 1952. Linear free energy relationships from rates of esterification and hydrolysis of aliphatic and orthosubstituted benzoate esters. J. Am. Chem. Soc. 74, 2729-2732.

Voudrias, E.A., Reinhard, M., 1988a. Reactivities of hypochlorous and hypobromous acid, chlorine monoxide, hypobromous acidium ion, chlorine, bromine, and bromine chloride in electrophilic aromatic substitution reactions with $p$-xylene in water. Environ. Sci. Technol. 22, 1049-1056.

Voudrias, E.A., Reinhard, M., 1988b. A kinetic model for the halogenation of $p$-xylene in aqueous hypochlorous acid solutions containing chloride and bromide. Environ. Sci. Technol. 22, 1056-1062.

Wang, P., He, Y.L., Huang, C.H., 2011. Reactions of tetracycline antibiotics with chlorine dioxide and free chlorine. Water Res. 45, 1838-1846.

Zhang, X.X., Zhang, T., 2011. Occurrence, abundance, and diversity of tetracycline resistance genes in 15 sewage treatment plants across China and other global locations. Environ. Sci. Technol. 45, 2598-2604.

Zarei, A.R., Sovizi, M.R., 2011. Application of cloud point extraction technique to preconcentration and spectrophotometric determination of free chlorine in water samples. J. Anal. Chem. 66, 269-274. 